\title{
RETROSPECTIVE EVALUATION OF BONE PAIN PALLIATION AFTER SAMARIUM-153-EDTMP THERAPY
}

\author{
Marcelo Tatit Sapienza, Carla Rachel Ono, Maria Inês Cury Guimarães, Tomoco \\ Watanabe, Paulo Aguirre Costa and Carlos Alberto Buchpiguel
}

SAPIENZA MT et al. Retrospective evaluation of bone pain palliation after samarium-153-EDTMP therapy. Rev. Hosp. Clín. Fac. Med. S. Paulo 59(6):321-328, 2004.

PURPOSE: The aim of this study was to evaluate the degree of metastatic bone pain palliation and medullar toxicity associated with samarium-153-EDTMP treatment.

METHODS: Seventy-three patients with metastatic bone pain having previously undergone therapy with samarium153-EDTMP ( $1 \mathrm{mCi} / \mathrm{kg})$ were retrospectively evaluated. Routine follow-up included pain evaluation and blood counts for 2 months after treatment. Pain was evaluated using a subjective scale (from 0 to 10) before and for 8 weeks after the treatment. Blood counts were obtained before treatment and once a week for 2 months during follow-up. Dosimetry, based upon the urinary excretion of the isotope, was estimated in 41 individuals, and the resulting radiation absorbed doses were correlated with hematological data.

RESULTS: Reduction in pain scores of $75 \%$ to $100 \%$ was obtained in 36 patients (49\%), with a decrease of $50 \%$ to $75 \%, 25 \%$ to $50 \%$, and $0 \%$ to $25 \%$ in, respectively, $20(27 \%), 10(14 \%)$, and $7(10 \%)$ patients. There was no significant relationship between the pain response and location of the primary tumor (breast or prostate cancer). Mild to moderate myelosuppression was noted in $75.3 \%$ of patients, usually with hematological recovery at 8 weeks. The mean bone marrow dose was $347 \pm 65 \mathrm{cGy}$, and only a weak correlation was found between absorbed dose and myelosuppression (Pearson coefficient $=.4$ ).

CONCLUSIONS: Samarium-153-EDTMP is a valuable method for metastatic bone pain palliation. A mild to moderate and transitory myelosuppression is the main toxicity observed after samarium therapy, showing a weak correlation with dosimetric measures.

KEYWORDS: Samarium. Pain. Scintigraphy. Palliative. Care. Neoplasm. Metastasis.

Bone metastases are common in the progression of various tumors such as prostate, breast, and lung carcinoma, and they often entail an occurrence of progressive pain. ${ }^{1}$ Control of pain and its consequences (eg, depression, movement constraint, and dependence) are important goals in oncological treatment requiring a multidisciplinary approach to the patient.

The use of ionizing radiation is one of the alternatives for pain treatment, together with the administration of drugs (eg, anti-inflammatories, opioids, chemotherapeutic drugs, receptor blockades, phosphonates) and surgical interventions. Local radiotherapy results in a good clinical response in approximately $80 \%$ of the cases (complete in $30 \%$ to $60 \%$ ) lasting for over 4 months, although with an effect confined to the irradiated

From the Radiology Institute, Hospital das Clínicas, Faculty of Medicine, University of São Paulo - São Paulo/SP, Brazil.

E-mail: mtsapienza@hotmail.com

Received for publication on October 24, 2003.

Accepted for publication on April 02, 2004. site. ${ }^{2,3}$ Hemibody radiotherapy (isolated or sequential) may be used in patients with widespread metastases, resulting in a complete response in approximately $20 \%$ of the cases, and a partial one for $50 \%$ to $100 \%$. Radiation on wide areas is limited by hematopoietic, pulmonary, and gastrointestinal toxicity produced by the high radiation absorbed dose., ${ }^{2,3}$

The irradiation of multiple bone lesions can also be achieved by the intravenous administration of beta-emitting isotopes with a high affinity for 
bone metastases. Beta radiation energy is almost completely delivered to the specific site of uptake, with a minimal effect on neighboring tissues. The main radioisotopes used for palliation of bone pain due to metastatic malignancies are strontium-89 and samarium-153, with response rates between $60 \%$ and $80 \% .^{2,4}$ The isotope most frequently used in Brazil is samarium153 due to its wide availability and low cost (150 dollars per treatment, compared to approximately 2,000 dollars for strontium-89).

$\mathrm{S}$ a m a ri u m-153-1 a b e led ethylenediaminetetramethylene phosphonic acid $\left({ }^{153} \mathrm{Sm}\right.$-EDTMP) is retained in the mineral phase of bone, probably by adsorption to hydroxyapatite crystals, similarly to the mechanism involved in the uptake of radiopharmaceuticals used in bone scans. Treatment with ${ }^{153} \mathrm{Sm}$-EDTMP was first described in $1989,{ }^{5}$ and it was first approved for clinical use in the USA in 1997. In Brazil, samarium-153 is produced by the Institute for Energetic and Nuclear Researches (IPEN Instituto de Pesquisas Energéticas e Nucleares - São Paulo) and has been used clinically since 1995, initially as part of an international program coordinated by the International Atomic Energy Agency (IAEA - Vienna), and later as a routine procedure covered by the Brazilian healthcare system (SUSSistema Único de Saúde).

Clinical response to treatment with ${ }^{153} \mathrm{Sm}$-EDTMP (pain reduction) is described in $55 \%$ to $88 \%$ of the cases, beginning 5 to 7 days after injection, and lasting for 2 to 17 weeks. $^{6,7,8}$ The shorter half-life of samarium-153 compared to strontium-89 (2 versus 50 days) may be related to the smaller interval for the response start (5 to 7 versus 10 to 20 days) and to its shorter duration ( 2 to 3 versus 3 to 4 months).

Bone marrow toxicity is the main adverse reaction observed after treatment with samarium-153, generally occurring in a mild to moderate degree, reaching a peak between 3 and 4 weeks and subsiding after 6 to 8 weeks. Grade III toxicity is described in approximately $10 \%$ of the patients treated with doses of $1 \mathrm{mCi} / \mathrm{kg},{ }^{9,10,11,12}$ and grade IV toxicity occurs in less than $1 \%$ of cases. In addition to betaparticle emission (energy $=810 \mathrm{keV}$ ), samarium-153 emits gamma radiation $($ energy $=103 \mathrm{keV})$, which may be used for biodistribution and dosimetric measures. A bone uptake of $55 \%$ to $75 \%$ of the injected dose is confirmed in these measurements, ${ }^{13,14}$ resulting in a radiation absorbed dose of approximately $7 \mathrm{cGy} / \mathrm{mCi}$ in normal bone and $42 \mathrm{cGy} / \mathrm{mCi}$ in osteoblastic bone lesions. $^{2}$

To the best of our knowledge, clinical results of the treatment with ${ }^{153} \mathrm{Sm}$-EDTMP in Brazil have not yet been described, even though there is almost one decade of experience.

The objectives of the current study were:

1- to evaluate the clinical response (pain intensity variation) and the marrow toxicity after treatment with ${ }^{153} \mathrm{Sm}$-EDTMP;

2- to correlate the degree of marrow toxicity with the radiation absorbed dose of the bone marrow.

\section{METHODS}

\section{Patients}

Medical records of 178 patients were retrospectively reviewed. Patients had been sent for treatment with ${ }^{153} \mathrm{Sm}$ EDTMP to the Nuclear Medicine Service of our Institute between 1995 and 2002. Patient records were considered adequate if there were data for at least $75 \%$ of the routine clinical and laboratory fields (daily pain evaluation and weekly blood counts for 8 weeks).

As part of the treatment planning, all patients had a consultation with a nuclear medicine physician to confirm the indications and to exclude eventual contraindications to the treatment, and all signed an informed consent. Indications for treatment were pain due to bone metastases requiring increasing analgesic doses, clinically uncontrolled pain, or recurring pain in a previously irradiated site. An additional criterion was the detection of multiple osteoblastic lesions in a recent bone scan (less than a 3-month interval) showing moderate to outstanding radiopharmaceutical uptake. Treatment was contraindicated for patients with one or more of the following criteria: severely disabled patients, leukopenia $\left(<2,500 / \mathrm{mm}^{3}\right)$ or thrombocytopenia $\left(<100,000 \mathrm{~mm}^{3}\right)$ in a recent blood test (less than 1 week), progressive drop of the platelet count, less than 1 month interval from chemotherapy or 2 months from radiotherapy involving more than $20 \%$ of the bone marrow, or pregnancy. Patients with pain due to a suspected pathological fracture, nerve compression, or soft tissue invasion were directed to complementary investigation and treatment with other modalities because treatment with ${ }^{153} \mathrm{Sm}$-EDTMP was not indicated.

\section{Treatment and follow-up}

Pain intensity before treatment was subjectively assessed by the patients themselves using a 0 -to- 10 scale $(0=$ no pain, $10=$ maximum pain). Analgesics used, their doses, and their use intervals were also recorded. Outpatient treatment was performed by the intravenous administration of ${ }^{153} \mathrm{Sm}$ EDTMP (IPEN - São Paulo, Brazil) through an upper limb access.

Routine follow-up included clinical and laboratory surveillance. Clinical surveillance consisted of daily pain intensity reporting for 8 weeks. The clinical response was appraised by comparing weekly pain intensity averages with the pretreatment value. Patients were 
grouped according to their pain intensity drop, that is, $0 \%$ to $25 \%, 25.1 \%$ to $50 \%, 50.1 \%$ to $75 \%$, and $75.1 \%$ to $100 \%$. Pain flare, a transitory worsening of pain after treatment, ${ }^{4,15}$ was defined by a greater-than-2-point increase in the pain scale within 5 days after the administration of ${ }^{153} \mathrm{Sm}$-EDTMP.

Blood counts were also obtained weekly during the same 8-week period, and the corresponding leukocyte count, platelet count, and hemoglobin concentration were recorded. Absolute and percent variations of these parameters were calculated compared to basal values (obtained at 1 week or less pretreatment). Medullary toxicity, based on the lowest leukocyte and platelet values observed during followup, was classified in accordance with the National Cancer Institute Common Toxicity Criteria - Version 1.

\section{Dosimetric calculations}

After the administration of ${ }^{153} \mathrm{Sm}$ EDTMP, 41 of the 73 patients underwent dosimetric calculation. Urinary excretion of samarium-153 by these 41 patients was measured hourly for 6 hours, and an activity retention curve was drawn. Previously described models ${ }^{16,17}$ were used to determine the activity distribution in the different intervals. These data were used to calculate the accrued activity integral in the cortical and trabecular bone using equation 1 , where $A=$ accrued activity, $A(t)=$ retained activity in each structure in the various times, $\ldots=$ intermediate terms between 1 and 24 hours, and $\lambda=$ the samarium-153 disintegration constant.

The radiation absorbed dose of the hematopoietic marrow resulting from the emission of beta particles from the isotope retained in the cortical and in the trabecular bone was calculated using equation 2 , where $S=$ radiation absorbed dose per accrued activity unit, $c o r=$ cortical bone, $t r a b=$ trabecular bone. The marrow radiation absorbed dose was corrected according to the patient's weight, based on the $70 \mathrm{~kg}$ and $170 \mathrm{~cm}$ reference-man (ICRP 23).

\section{Statistical evaluation}

Mean and standard deviation of the initial pain intensity, clinical response, and medullary toxicity were estimated for the whole group of patients. The Student $t$ test was used to compare pain intensity prior to and at the end of the eighth week after treatment (1-tailed paired $t$ test, $P<.05$ ), as well as to compare the treatment response between patients with primary breast or prostate cancer (2-tailed $t$ test, $P<.05$ ). The relationship between the decrease in platelet and leukocyte counts and the radiation absorbed dose of the bone marrow was evaluated using Pearson's linear correlation coefficient.

\section{RESULTS}

Medical records were considered appropriate for analysis in 73 patients (37 males and 36 females; age range, 31 to 89 years, mean $\pm \mathrm{SD}, 60 \pm 15$

\section{Equation 1}

$$
\bar{A}=\frac{1}{\lambda}\left[\frac{A_{\left(t_{1}\right)}}{2}\left(1-e^{-\lambda t_{1}}\right)+\ldots+\frac{A_{\left(t_{24}\right)}+A_{\left(t_{\infty}\right)}}{2}\left(e^{-24 \lambda}\right)\right]
$$

Equation 2

$$
\left.D_{R M}=0.5 \bar{A}_{s k} \times S_{(R M} \leftarrow \text { cor }\right)+0.5 \bar{A}_{s k} \times S(R M \leftarrow \text { trab })
$$

years) who had the following as a primary tumor: prostate carcinoma $(\mathrm{n}=$ $36)$, breast carcinoma $(\mathrm{n}=29)$, lung carcinoma $(n=5)$, colorectal carcinoma $(\mathrm{n}=1)$, parathyroid carcinoma $(\mathrm{n}=1)$, or unknown primary tumor ( $\mathrm{n}$ =1). Patient records were considered inappropriate for analysis in the remaining 105 patients (62 followed up at Hospital das Clínicas de São Paulo; 43 at other institutions).

The mean value for pain intensity dropped from $7.1 \pm 2.8$ to $3.4 \pm 2.8$ in the first 2 weeks after treatment, holding at $3.0 \pm 2.3$ in the eighth week after treatment (Figure 1). Pain intensity in the eighth week after treatment was significantly lower than pain before treatment $(P<.001)$.

During follow-up, a maximum pain intensity reduction of $5.83 \pm 2.13$ points with respect to the initial value (percent reduction: $70.5 \% \pm 27.7 \%$ ) was observed. A $75 \%$ to $100 \%$ pain reduction occurred in 36 patients (49\%), and a $50 \%$ to $75 \%$ reduction occurred in 20 cases $(27 \%)$. Pain reduction was less than $50 \%$ in the other cases $(25 \%$ to $50 \%$ in 10 cases and $0 \%$ to $25 \%$ in 7 cases) (Figure 2). No statistical difference was observed in pain intensity reduction either in absolute scale $(P=$ $.983)$ or in percent scale $(P=.069)$ when patients with prostate and breast carcinoma were compared.

In 7 patients, a transitory worsening of pain was observed during the first week after treatment, with a mean increase of $3.76 \pm 0.78$ in the pain scale. The response subsequently observed in this subset of patients was similar to that seen in the others (reduction of $70 \% \pm 35 \%$ compared to the initial pain intensity).

Pretreatment blood count values were as follows: hemoglobin $=11.5 \pm$ $2.0 \mathrm{~g} / \mathrm{dL}$, leukocytes $=6,820 \pm 3,480 /$ $\mathrm{mm}^{3}$, and platelets $=237,200 \pm$ $95,000 / \mathrm{mm}^{3} .75 .3 \%$ of the patients experienced leukopenia and/or thrombocytopenia during follow-up: $71.2 \%$ of 


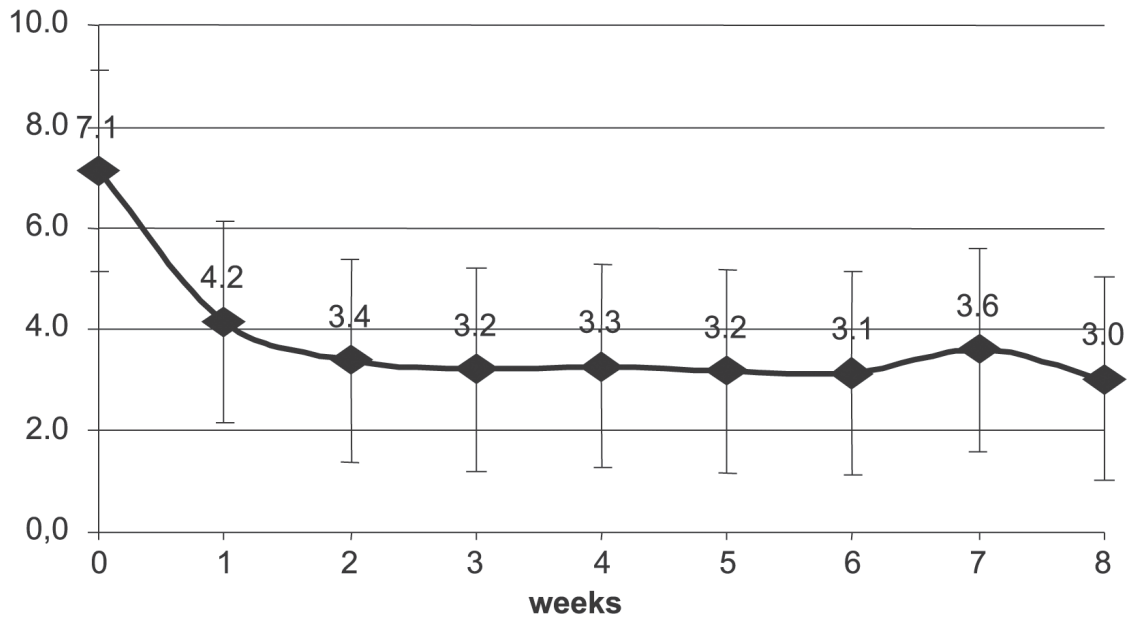

Figure 1 - Pain intensity before and for 8 weeks after treatment with ${ }^{153} \mathrm{Sm}$-EDTMP.

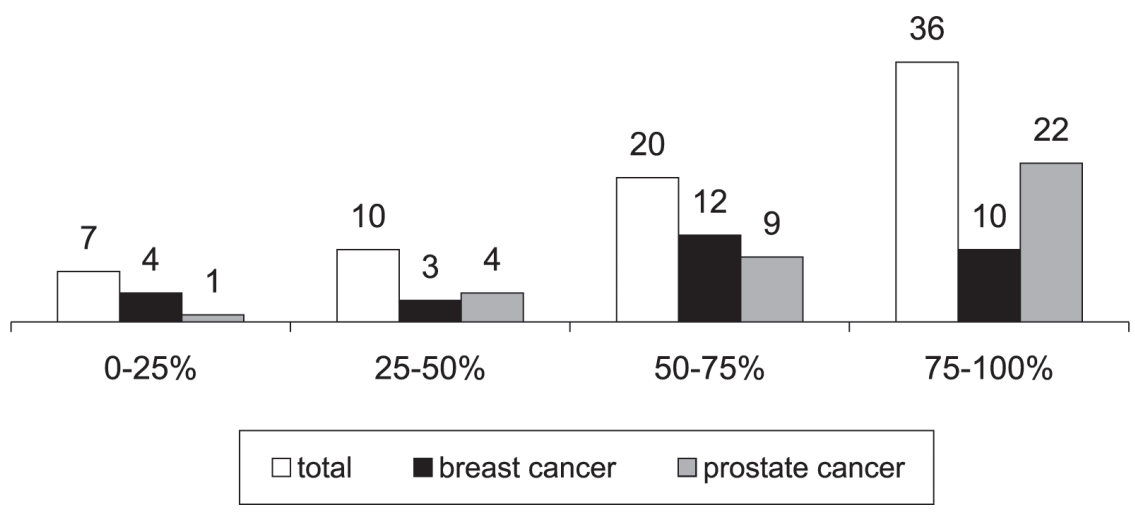

Figure 2 - Percent decrease in pain intensity after treatment with ${ }^{153} \mathrm{Sm}$-EDTMP.

the patients had leukopenia (grade I toxicity $=26.0 \%$, grade $\mathrm{II}=28.8 \%$, grade III $=16.4 \%$ ); and $53.4 \%$ had thrombocytopenia (grade I toxicity $=$ $15.1 \%$, grade $\mathrm{II}=17.8 \%$, grade $\mathrm{III}=$ $19.2 \%$, grade IV $=1.4 \%$ ) (Figure 3 ) Leukopenia and thrombocytopenia occurred simultaneously in 36 cases, while isolated leukopenia or thrombocytopenia occurred, respectively, in 16 and 3 patients. Platelet count variation was only weakly correlated with leukocyte count variation (Pearson's coefficient $r=.41$ ). The correlation between the minimum and basal values was also low for both leukocyte and platelet counts ( $r=.30$ and .62).

The platelet and leukocyte nadir occurred between 4 and 5 weeks after treatment, with recovery to $78 \%$ of basal leukocyte values (average $\pm \mathrm{SD}=$ $4,910 \pm 1,830 / \mathrm{mm}^{3}$ ) and $88 \%$ of basal platelet values $(187,700 \pm 81,500 /$ $\mathrm{mm}^{3}$ ) at the end of the eighth week (Figure 4). Persistent leukopenia was still present between the seventh and the eighth weeks in $26 \%$ of the cases (4\% had between 1,000 and 2,000 leukocytes $/ \mathrm{mm}^{3}, 8 \%$ had between 2,000 and 3,000 leukocytes $/ \mathrm{mm}^{3}$, and $14 \%$ had between 3,000 and 4,000 leukocytes $/ \mathrm{mm}^{3}$ ). Thrombocytopenia was still present in $16 \%$ of cases $(4 \%$ had between 25 and 50 thousand platelets $/ \mathrm{mm}^{3}, 4 \%$ had between 50 and 75 thousand platelets $/ \mathrm{mm}^{3}$, and $8 \%$ had between 75 and 100 thousand platelets $/ \mathrm{mm}^{3}$ ).
The radiation absorbed dose of bone marrow varied from 195 to 468 cGy (mean $\pm \mathrm{SD}=347 \pm 65 \mathrm{cGy}$ ) in the 41 patients. The radiation absorbed dose had a low correlation with the maximum decrease in leukocyte counts during follow-up (Pearson's coefficient $r=.40$ ), as well as with the maximum drop in platelet counts (Pearson's coefficient $r=.48$ ).

\section{DISCUSSION}

Intravenous injection of strontium89 and samarium-153 for the treatment of pain due to osteoblastic metastasis has been widely described in the literature, mainly for patients with hormone-refractory prostate carcinoma or with breast carcinoma, with reported responses between $55 \%$ and $83 \%$ of patients. ${ }^{1,5,6,7,15,18,19-22}$ The clinical response observed in this study was similar to that described in literature, the pain having been reduced to less than $50 \%$ of basal levels in $76 \%$ of cases, with no distinction as to the primary tumor (breast or prostate). Pain improvement after treatment is probably related to a reduction in both inflammatory infiltrate and cytokine release, together with a change in osteoclastic and osteoblastic function. Pain increase during the first week after treatment (a phenomenon known as "pain flare" and probably related to cytokine release) was observed in $10 \%$ of patients, a value comparable to that described in the literature. ${ }^{15}$

Our findings of bone marrow toxicity were also similar to those described in the literature, with leukopenia in $71.2 \%$ of patients and thrombocytopenia in $53.4 \%$ of our patients. Concentration of leucocytes and platelets reached a nadir between 4 and 5 weeks after treatment. There was a good recovery in blood counts during follow-up, reaching $78 \%$ of initial leukocyte count and $88 \%$ of initial 
a)

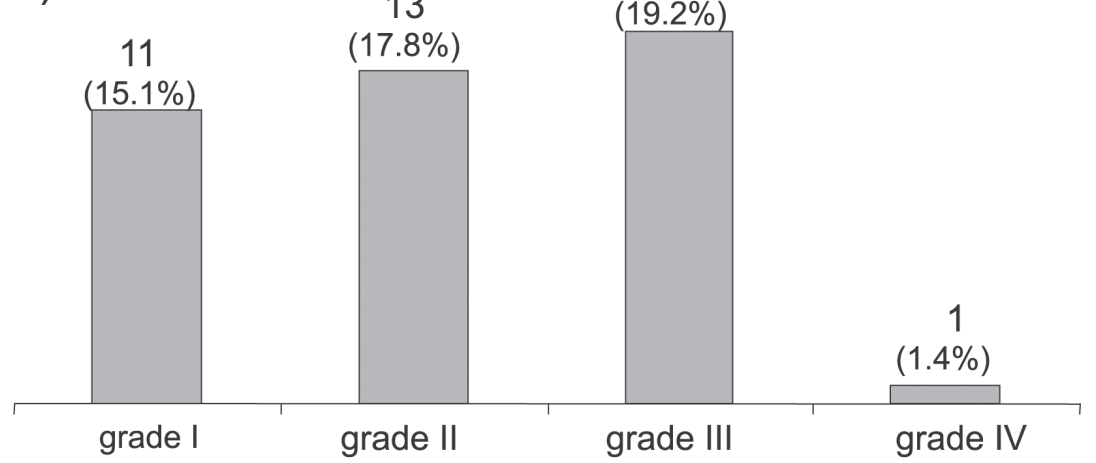

* in accordance with the National Cancer Institute Common Toxicity Criteria-Version1 (grade $\mathrm{I}=75-100,000, \mathrm{II}=50-75,000, \mathrm{II}=25-50,000, \mathrm{IV}=0-25,000$ platelets $/ \mathrm{mm}^{3}$ )

b)

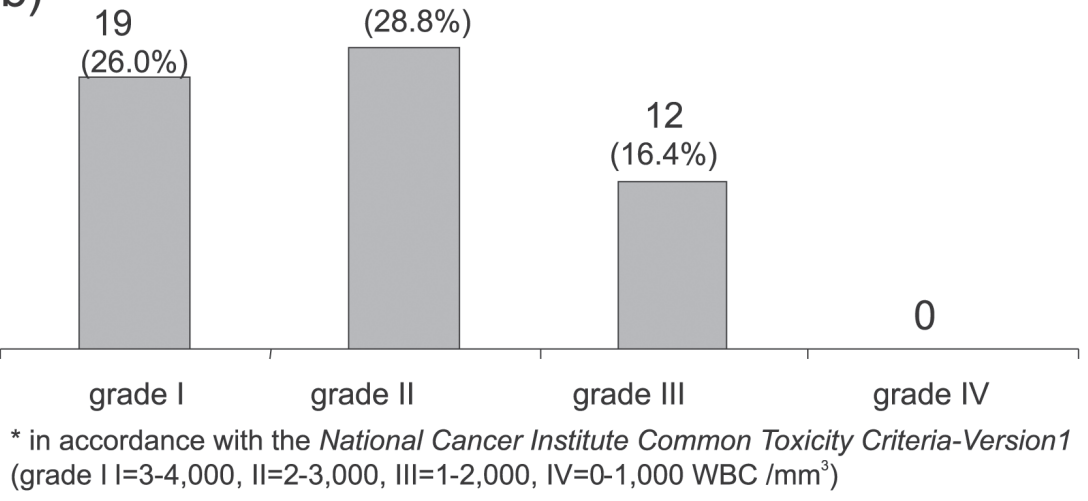

Figure 3 - a) Number of patients with medullary toxicity after treatment with ${ }^{153} \mathrm{Sm}$ EDTMP (characterized by thrombocytopenia)*. b) - Number of patients with medullary toxicity after treatment with ${ }^{153} \mathrm{Sm}$-EDTMP (characterized by leucopenia)*.

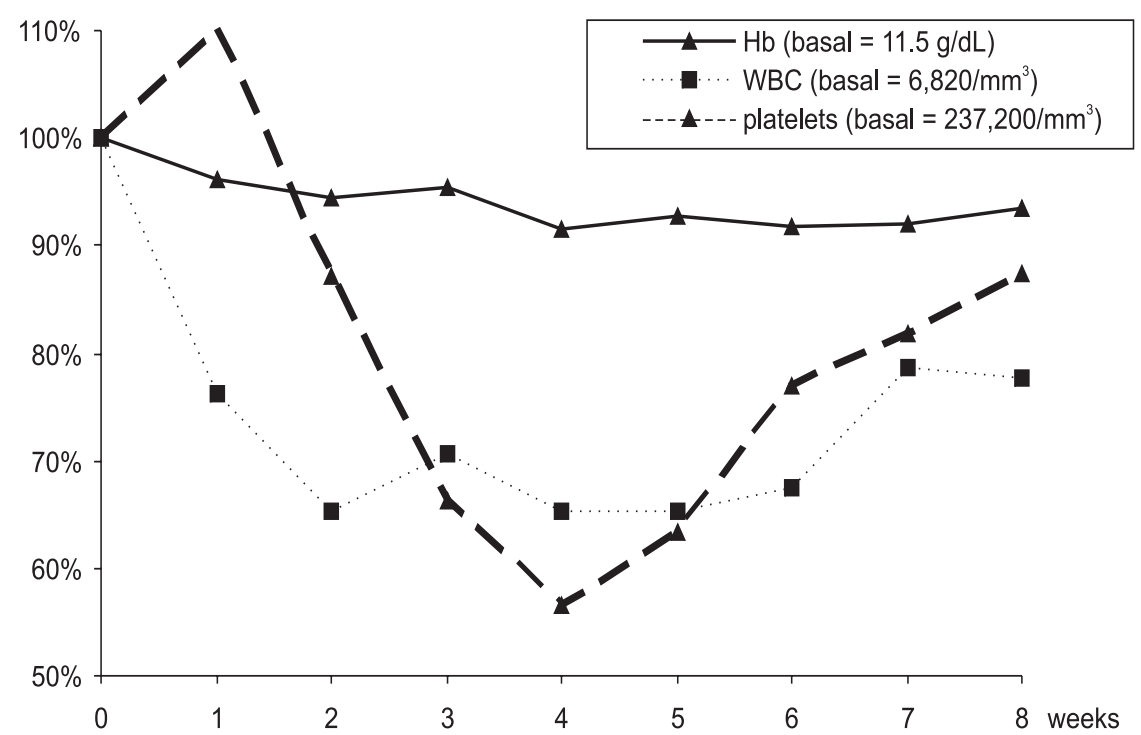

Figure 4 - Blood counts before and for 8 weeks after treatment with 153Sm-EDTMP. platelet count. In addition to the risks of leukopenia and thrombocytopenia, long-lasting marrow depression is a reason for concern because it may cause difficulty in future treatments with cytostatic agents. Even though leukopenia persisted in $26 \%$ of patients and thrombocytopenia in $16 \%$, it is difficult to determine if medullary function was permanently jeopardized, since further improvement in laboratory parameters may have occurred after the 8-week follow-up. On the other hand, bone marrow infiltration by the primary disease and the effect of previous chemotherapy could also contribute to the nonreversion of the medullary depression.

The usual activity for treatment with samarium-153-EDTMP is $1 \mathrm{mCi}$ / kg. ${ }^{10,11,23}$ With this activity, various authors describe the radiation absorbed dose in the marrow to be between 230 and $590 \mathrm{cGy}^{16,18,21,24}$ (a range that includes the results of this study, ie, 347 \pm 65 cGy). Administration of doses above $1 \mathrm{mCi} / \mathrm{kg}$ seems not to lead to better pain control, ${ }^{9}$ even though it results in higher marrow toxicity. ${ }^{9,12,15,24}$ Though other studies have shown that administration of higher activities increases the risk of bone marrow toxicity, ${ }^{9,24,25}$ the current study did not show a direct correlation between toxicity and individual dosimetric measures. The low correlation observed suggests that other factors not evaluated in this study (such as previous chemotherapy, radiotherapy, and the extent of bone metastasis) could have reduced the bone marrow reserve, thus increasing the radiopharmaceutical toxicity.

Retrospective analysis imposed several restrictions on the current study, some of which were due to the fact that the follow-up file card had been designed approximately 8 years ago. We particularly regret that fields were not included for the clinical findings of medullary toxicity (febrile neutropenia, bleeding, and transfusions) 
and for the objective evaluation of clinical parameters (for instance, Karnofsky's index of clinical performance). The comparison of average weekly pain intensity with the pretreatment value had the purpose of reducing the interference of natural oscillations on pain intensity. Additionally, it should be noted that the initial pain score was based on an isolated evaluation; thus, a bias may have occurred due to a return to the average during follow-up.

The possibility of a selection bias must also be considered since it is more probable that patients with an unsatisfactory response to treatment would fail to complete follow-up. Though these data were not included in the current study, we observed that patients with incomplete information were prone to higher pain intensity in the basal evaluation (8.64 \pm 2.0 points) and to a lower response intensity (average reduction of $4.4 \pm 2.7$ points).

In addition to the difficulties peculiar to retrospective data collections and the lack of a control group, this study also had limitations inherent to the type of clinical situation evaluated, including the possible simultaneous or sequential use of other therapies and the interference of patients' activities according to pain intensity. We considered patients' basal situations as a reference for the evaluation of clinical response and of adverse reactions during follow-up, and it is our experience that other treatments are generally introduced before the indication for samarium-153-EDTMP. It should be noted that there was no overlapping of chemotherapy, introduction of steroids, or hormone therapy in the period comprising the previous month and the 2 follow-up months after samarium-153-EDTMP administration-factors that could interfere in the response and adverse reactions analysis. There were analgesic consumption changes during the follow-up period, with a tendency towards reduction in the dose and frequency of use among patients with a pain reduction higher than $50 \%$; this suggests that the observed response had effectively originated from use of samarium-153EDTMP. However, analgesic types, doses, and use intervals were incompletely reported in almost all cases and therefore could not be included in the results.

\section{CONCLUSIONS}

Treatment with ${ }^{153} \mathrm{Sm}$-EDTMP resulted in a good clinical response with a reduction in the subjective appraisal of pain to less than $50 \%$ of the basal intensity in $76 \%$ of the patients.

The main adverse effect observed during follow-up was a transitory medullary depression to a mild to moderate degree that was only weakly correlated with dosimetric measures. Leukopenia was observed in $71.2 \%$ of the patients and thrombocytopenia in $53.4 \%$; however, most of the patients had recovered at the end of the eighth week.
SAPIENZA MT e col. Avaliação retrospectiva do tratamento da dor óssea metastática com Samário-153EDTMP. Rev. Hosp. Clín. Fac. Med. S. Paulo 59(6):321-328, 2004.

OBJETIVO: O presente trabalho teve por objetivo avaliar o efeito paliativo da dor e a toxicidade medular associados ao tratamento com Samário153-EDTMP em pacientes com metástases ósseas.

MÉTODOS: O estudo foi realizado de forma retrospectiva, a partir do levantamento de prontuário de 178 pacientes submetidos a tratamento com $1 \mathrm{mCi} / \mathrm{kg}$ de ${ }^{153} \mathrm{Sm}$-EDTMP devido à dor por metástases ósseas. Os prontuários de 73 pacientes foram considerados adequados para análise dos parâmetros clínicos (intensidade da dor) e laboratoriais (hemograma). A intensidade da dor foi avaliada em escala de 0 a 10 pelo próprio paciente, antes e durante 8 semanas após o tratamento. Hemograma completo foi realizado antes do tratamento e a cada semana nas 8 semanas seguintes. Estudos de dosimetria foram realizados em 41 dos 73 pacientes, baseados na excreção urinária e retenção do radio- isótopo, sendo a dose de radiação absorvida correlacionada à toxicidade medular.

RESULTADOS: Redução importante na intensidade da dor (diminuição de 75 a $100 \%$ do basal) foi constatada em 36 pacientes (49\%), com redução de $50-75 \%$, $25-50 \%$ e $0-25 \%$ em, respectivamente, 20 (27\%), 10 $(14 \%)$ e $7(10 \%)$ casos. Não se observou variação significativa da resposta entre os pacientes com tumor primário de mama $(n=29)$ ou de próstata $(n=36)$. Toxicidade medular foi observada em $75,3 \%$ dos pacientes $(71,2 \%$ com leucopenia e $53,4 \%$ com plaque- 
topenia), em geral de grau leve a moderado e com recuperação ao término da $8^{\circ}$ semana. A dose média de medula foi de $347 \pm 65$ cGy, havendo baixa correlação entre a dosimetria medular e a queda da contagem de leucócitos (coeficiente de correlação linear de 0,40 ) ou de plaquetas (coeficiente de correlação linear $=0,48)$.

CONCLUSÕES: O tratamento com Samário-153-EDTMP permitiu um adequado controle da dor por metástases ósseas, com significativa redução na intensidade da dor. A toxicidade medular transitória foi a principal reação adversa observada, em geral de grau leve a moderado, apresentando baixa correlação com as medidas dosimétricas.

UNITERMOS: Samário. Dor. Cintilografia. Assistência paliativa. Metástase.

\section{REFERENCES}

1. Coleman RE. Skeletal complications of malignancy. Cancer 1997;80:1588-94.

2. Mcewan AJ. Use of radionuclides for the palliation of bone metastases. Semin Radiat Oncol 2000;10:103-14.

3. Saarto T, Janes R, Tenhunen M, Kouri M. Palliative radiotherapy in the treatment of skeletal metastases. Eur J Pain 2002;6:32330 .

4. Silberstein EB, Eugene L, Saenger SR. Painful osteoblastic metastases: the role of nuclear medicine. Oncology (Huntingt) $2001 ; 15: 157-63$

5. Turner JH, Claringbold PG, Hetherington EL, Sorby P, Martindale AA. A phase I study of samarium-153 ethylenediaminetetramethylene phosphonate therapy for disseminated skeletal metastases. J Clin Oncol 1989;7:1926-31.

6. Collins C, Eary JF, Donaldson G, Vernon C, Bush NE, Petersdorf $\mathrm{S}$, et al. Samarium-153-EDTMP in bone metastases of hormone refractory prostate carcinoma: a phase I/II trial. J Nucl Med 1993;34:1839-44.

7. Sandeman TF, Budd RS, Martin JJ. Samarium-153-labelled EDTMP for bone metastases from cancer of the prostate. Clin Oncol (R Coll Radiol ) 1992;4:160-4.

8. Lovera C, Massardo T, Galleguillos MC, et al. [Analgesic response and secondary effects in patients with osteoblastic metastasis, treated with Samarium-153 ethylenediaminotetramethylenephosphate]. Rev Med Chil 1998;126:963-71.

9. Alberts AS, Smit BJ, Louw WK, van Rensburg AJ, van Beek A, Kritzinger V, et al. Dose response relationship and multiple dose efficacy and toxicity of samarium-153-EDTMP in metastatic cancer to bone. Radiother Oncol 1997;43:175-9.

10. Serafini AN, Houston SJ, Resche I, Quick DP, Grund FM, Ell PJ, et al. Palliation of pain associated with metastatic bone cancer using samarium-153 lexidronam: a double-blind placebocontrolled clinical trial. J Clin Oncol 1998;16:1574-81.

11. Resche I, Chatal JF, Pecking A, Ell P, Duchesne G, Rubens R, et al. A dose-controlled study of $153 \mathrm{Sm}$-ethylenediaminetetramethylenephosphonate (EDTMP) in the treatment of patients with painful bone metastases. Eur J Cancer 1997; $33: 1583-91$
12. Tian JH, Zhang JM, Hou QT, Oyang QH, Wang JM, Luan ZS, et al. Multicentre trial on the efficacy and toxicity of single-dose samarium-153-ethylene diamine tetramethylene phosphonate as a palliative treatment for painful skeletal metastases in China. Eur J Nucl Med 1999;26:2-7.

13. Singh A, Holmes RA, Farhangi M, Volkert WA, Williams A, Stringham LM, et al. Human pharmacokinetics of samarium153 EDTMP in metastatic cancer. J Nucl Med 1989;30:18148.

14. Bartlett ML, Webb M, Durrant S, Morton AJ, Allison R, Macfarlane DJ. Dosimetry and toxicity of Quadramet for bone marrow ablation in multiple myeloma and other haematological malignancies. Eur J Nucl Med Mol Imaging 2002;29:1470-7.

15. Farhanghi M, Holmes RA, Volkert WA, Logan KW, Singh A. Samarium-153-EDTMP: pharmacokinetic, toxicity and pain response using an escalating dose schedule in treatment of metastatic bone cancer. J Nucl Med 1992;33:1451-8.

16. Logan KW, Volkert WA, Holmes RA. Radiation dose calculations in persons receiving injection of samarium-153 EDTMP. J Nucl Med 1987;28:505-9.

17. Turner JH, Martindale AA, Sorby P, Hetherington EL, Fleay RF, Hoffman RF, et al. Samarium-153 EDTMP therapy of disseminated skeletal metastasis. Eur J Nucl Med 1989;15:78495 .

18. Cameron PJ, Klemp PF, Martindale AA, Turner JH. Prospective 153Sm-EDTMP therapy dosimetry by whole-body scintigraphy. Nucl Med Commun 1999;20:609-15.

19. Friedland J. Local and systemic radiation for palliation of metastatic disease. Urol Clin North Am 1999;26:391-402, x.

20. Altman GB, Lee CA. Strontium-89 for treatment of painful bone metastasis from prostate cancer. Oncol Nurs Forum 1996;23:523-7.

21. Eary JF, Collins C, Stabin M, Vernon C, Petersdorf S, Baker M, et al. Samarium-153-EDTMP biodistribution and dosimetry estimation. J Nucl Med 1993;34:1031-6.

22. Ahonen A, Joensuu H, Hiltunen J, Hannelin M, Heikkila J, Jakobsson M, et al. Samarium-153-EDTMP in bone metastases. J Nucl Biol Med 1994;38:123-7. 
23. Serafini AN. Systemic metabolic radiotherapy with samarium153 EDTMP for the treatment of painful bone metastasis. Q J Nucl Med 2001;45:91-9.

24. Bayouth JE, Macey DJ, Kasi LP, Fossella FV. Dosimetry and toxicity of samarium-153-EDTMP administered for bone pain due to skeletal metastases. J Nucl Med 1994;35:63-9.
25. Anderson PM, Wiseman GA, Dispenzieri A, Arndt CA, Hartmann LC, Smithson WA, et al. High-dose samarium-153 ethylene diamine tetramethylene phosphonate: low toxicity of skeletal irradiation in patients with osteosarcoma and bone metastases. J Clin Oncol 2002;20:189-96. 